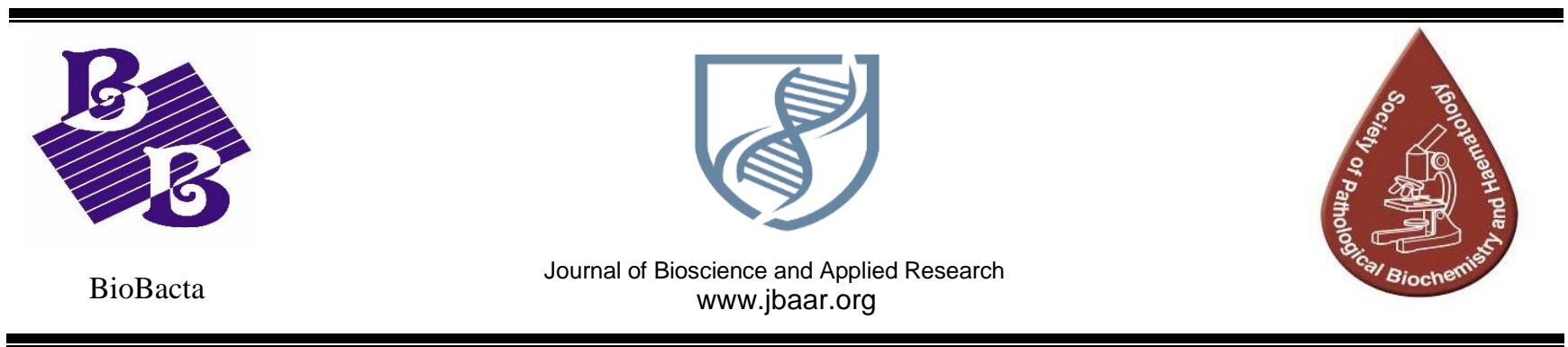

\title{
The Correlation between Single Nucleotide Polymorphism of MBOAT7 and PNPLA3 Genes to The Degree of Hepatic Fibrosis in HCV Patients: An Experience from Egypt
}

\author{
Samar Samir Youssef ${ }^{1 *}$, Eman Abd El Razek Abbas', Yasser Hamada Aly², Sameh Seif ${ }^{3}$ \\ 1. Department of Microbial Biotechnology, National Research Centre, Dokki, Egypt. \\ 2. Department of Endemic Medicine, Cairo University. \\ 3. National Hepatology and Tropical Medicine Research Institute, Cairo, Egypt
}

Corresponding author:

Prof: Samar Samir Youssef:

Email: samaryoussef67@gmail.com, SS.youssef@nrc.sci.eg

Microbial biotechnology Department National Research Centre, Dokki, Cairo

ORCID of the corresponding author: orcid.org/0000-0001-7114-4325

DOI: 10.21608/jbaar.2020.135612

\begin{abstract}
Objectives: To detect the correlation between the single nucleotide polymorphisms (SNPs) in MBOAT7 and PNPLA3 genes and hepatic fibrosis in hepatitis $\mathrm{C}$ virus (HCV) Egyptian patients, and to highlight the additive effect, if any, of MBOAT7 on the correlation of PNPLA3 polymorphism with liver fibrosis in HCV patients from Egypt. Methods: In this cross-sectional study, we recruited treatment-naïve patients with chronic HCV. The rs738409 (PNPLA3) and rs641738 (MBOAT7) polymorphisms were assessed by Real-Time PCR. We utilized the METAVIR-Score to classify the degree of hepatic fibrosis and necroinflammatory activity.

Results: A total of 93 patients (mean age $42.72 \pm 10.46$; males $=49.5 \%$ ) were included. Our analysis showed that $10.8 \%$ of the patients had GG genotype of the PNPLA3 gene and $46.2 \%$ had TT genotype of the MBOAT7 gene. Compared to combined CC and GC genotypes, carriers of GG genotype in the PNPLA3 gene were more likely to be males ( $p=0.041$ ), have higher fibrosis grade ( $p=0.043$ ), have higher serum creatinine ( $p=0.036)$, higher TSH ( $p=0.017$ ) and higher viral load $(\mathrm{p}=0.045)$. Notably, we found a significant association between TT genotype in MBOAT7 and advanced fibrosis only (but not with necroinflammation ( $\mathrm{p}>0.05$ ). Our multivariate analysis showed that the GG genotype in the PNPLA3 gene and TT genotype in the MBOAT7 gene were independent predictors of advanced fibrosis. Conclusion: PNPLA3 GG genotype and MBOAT7 TT genotype are independent predictors for hepatic fibrosis, and thus might be linked to faster disease progression.
\end{abstract}

Keywords: Chronic HCV; Fibrosis; Cirrhosis; MBOAT7; PNPLA3

Received: October 1, 2020. Accepted: December 15, 2020. Published: December 20, 2020 


\section{Introduction}

Hepatitis $\mathrm{C}$ virus (HCV) infection is the leading cause of chronic hepatitis $\mathrm{C}$ (CHC), liver cirrhosis, and hepatocellular carcinoma (HCC), with 130-170 million people infected, accounting for almost 3\% of the world's population $(1,2)$. To date, there is no clear understanding of human variation for susceptibility and severity of the liver injury. The rising incidence of liver diseases, high individual differences in the course of diseases, and rapid development of genotyping technologies led to several genetic studies that demonstrated the importance of genetic factors in the development and progression of chronic liver injury (3-5).

Using techniques of next-generation sequencing, genome-wide association studies (GWASs) are now commonly conducted to establish associations between single nucleotide polymorphisms (SNPs), and the risk for various diseases (6). Over the last decade, there have been major GWASs over hepatology which revealed genetic susceptibility to liver diseases (3).

Moreover, many studies demonstrated that the polymorphism of the patatin-like phospholipase domain containing 3 (PNPLA3) gene SNP, also known as adiponutrin, is linked with liver injury, steatosis, elevated liver enzymes, fibrosis, and $\operatorname{HCC}(7,8)$. This SNP causes a replacement of isoleucine with methionine at position 148 (I148M) (9,10). Earlier studies of $\mathrm{G}$ and $\mathrm{C}$ alleles of the PNPLA3 gene showed different patterns in steatosis and fibrosis in $\mathrm{CHC}$ $(11,12)$. The data are heterogeneous and indicate that populations vary in the allele frequency and steatogenic effect of PNPLA3 variants (9). Fan et al. (2016) conducted a meta-analysis, which showed that PNPLA3 $(\mathrm{C}>\mathrm{G})$ was linked with the risk of both steatosis and advanced liver fibrosis in patients with $\mathrm{CHC}$, especially among the Caucasian population (13).
Moreover, an intronic SNP in the membrane-bound O-acyltransferase domain-containing protein 7 (MBOAT7) (rs641738) has been observed to act as risk loci for alcoholic liver disease-related cirrhosis and non-alcoholic fatty liver disease (NAFLD) (12). Recent researches also showed that in $\mathrm{CHC}, M B O A T 7$ rs641738 SNP was an independent predictor of serious liver steatosis $(14,15)$. Despite the importance of these SNPs, there is no enough evidence regarding their association with liver fibrosis in the Middle East and African countries. Therefore, in this study, we aimed to detect the correlation between the SNPs in MBOAT7 and PNPLA3 genes and fibrosis in $\mathrm{HCV}$ Egyptian patients, and to highlight the additive effect, if any, of MBOAT7 on the correlation of PNPLA3 polymorphism with liver fibrosis in $\mathrm{HCV}$ patients from Egypt.

\section{Material and Methods:}

\section{Design and Population}

In this cross-sectional study, we recruited adult patients (aged >18 years old) with $\mathrm{CHC}$ from outpatient clinics of the National Hepatology and Tropical Medicine Research Institute (NHTMRI), Cairo, Egypt within the period from September 2019 to February 2020. The establishment of $\mathrm{CHC}$ was based on the findings of laboratory investigations, imaging, and liver biopsy. Only patients with no previous history of direct antiviral agents (DAAs) intake were deemed eligible. We excluded patients with known human immunodeficiency virus infection, hepatitis B surface antigen-positive test, hepatocellular carcinoma, advanced liver decompensation, and/or previous organ transplant. Patients who were submitted to hemodialysis were excluded as well. Eligible patients were enrolled after they signed the written informed consent.

Data Collection and laboratory investigations: 
The following data were collected from eligible patients: age, gender, anthropometric measures, complete blood count (CBC), serum alanine aminotransferase (ALT), aspartate aminotransferase (AST), total bilirubin, serum albumin, alphafetoprotein (AFP), alkaline phosphatase (ALP), serum creatinine, blood glucose level, and the viral load of $\mathrm{HCV}$. For laboratory investigations, $10 \mathrm{~mL}$ of venous blood was withdrawn after eight hours of fasting and then centrifuged.

\section{Genetic testing}

The extraction and purification of genomic DNA from the plasma were conducted using a QIAamp DNA Blood Mini kit (Qiagen \#51104) according to the manufacturer's instructions and preserved at $-80^{\circ}$ $\mathrm{C}$ for genetic determinations.

After DNA extraction, the samples of all patients were subjected to the real-time PCR reaction to analyze the polymorphism of the genes and the initial step was to bring the concentration of DNA of each sample to $20 \mathrm{ng} / \mu 1$. So, samples were diluted to reach this value. Then, genotyping of the studied genes was performed for all patients by real-time PCR and using the system "Taqman allelic discrimination assay" on Agilent Mx3000p qPCR, real-time PCR (Agilent Technologies, Germany). The assay was standardized in a final volume of $25 \mu \mathrm{l}: 12.5 \mu \mathrm{l}$ of $2 \mathrm{x}$ TaqMan Universal MasterMix II, no UNG (Applied Biosystems, USA), $1.25 \mu 1$ of Genotyping Assay 20x, $10.25 \mu \mathrm{l}$ of Dnase free water (Promega, USA), and 1 $\mu 1$ of genomic DNA. The cycling was as follows: $95^{\circ} \mathrm{C}$ for $10 \mathrm{~min}$, followed by 40 cycles of $95^{\circ} \mathrm{C}$ for $15 \mathrm{~s}$ and $60^{\circ} \mathrm{C}$ for $1 \mathrm{~min}(16)$. The interpretation of genotypes for MBOAT7 and PNPLA3 was given by (GG, GT, TT and GG, CC, CG respectively).

\section{Assessment of Liver Fibrosis}

Fibrosis was mainly assessed by the FIB4 score. Some patients had a biopsy report assessed by the
Metavir scoring system. The processing and assessment of liver biopsies were done by independent pathologists, who were not aware of the genetic testing findings. The handling and processing of liver biopsies were done according to the standard protocol of the National Hepatology and Tropical Medicine Research Institute (NHTMRI), Cairo, Egypt; all biopsies were stained by $\mathrm{H} / \mathrm{E}$, chrome aniline blue, and Prussian blue iron stain. We utilized the METAVIR-Score to classify the degree of hepatic fibrosis, with a grading system based on nominal categories from F0 (no fibrosis) to F4 (cirrhosis), and necroinflammatory activity, with a grading system based on nominal categories from A0 (absent) to A3 (severe)(17).

\section{Statistical analysis:}

The SPSS version 20.0 (SPSS Inc., Chicago, Illinois, USA) was used for data analysis. The continuous and dichotomous data were summarized in the form of the mean \pm standard deviation (SD) and frequency (percentages), respectively. The association between continuous and dichotomous data was examined by independent-samples t-test or MannWhitney test. A chi-squared test was applied to test the hypotheses in categorical variables. The odds ratio (OR) and 95\% confidence interval (CI) were calculated to assess the risk of SNPs amongst different categorical variables. The null hypothesis was rejected when the p-value at a level less than 0.05 .

\section{Results}

\section{Characteristics of studied patients}

A total of 93 patients (mean age $42.72 \pm 10.46$; males $=49.5 \%)$ were included. The mean serum AST and ALT were $40.94 \pm 28.44$ and $36.61 \pm 25.05 \mathrm{U} / \mathrm{mL}$, respectively (Table 1). Twenty-seven patients (29\%) had fibrosis grade 3 and 12 patients (12.9\%) had fibrosis grade 4 . In addition, 29 patients $(31.40 \%)$ had A2-A3 necroinflammatory activities. 
PNPLA3 and MBOAT7 genotypes distribution totally and according to fibrosis

The prevalence of SNPs genotypes in our analysis showed that $10.8 \%$ of patients had the risk GG genotype of PNPLA3 gene and $46.2 \%$ had the risk TT genotype of the MBOAT7 gene (Table 2).

When the genotypes of these polymorphisms were stratified according to fibrosis, results showed that patients with GG genotype of PNPLA3 were more likely to have F4 fibrosis than patients with homozygous or heterozygous $\mathrm{C}$ allele $(30 \%$ versus $10.8 \%, \mathrm{p}=0.043$; Figure 1, Table $3 \mathrm{~A})$. The TT genotype of MBOAT7 showed significant association $(\mathrm{p}=0.032)$ with advanced fibrosis (F4) only but not with fibrosis as seen in table 3 B. On the contrary, we found no significant association between necroinflammation and rs738409 (PNPLA3) polymorphism ( $\mathrm{p}=0.335$; Table $3 \mathrm{~A}$ ).

Our univariate analysis indicated that only the GG genotype in the PNPLA3 gene was a significant predictor of $\mathrm{F} 4$ fibrosis ( $\mathrm{p}=0.03$ ). The multivariate, stepwise, analysis showed that the GG genotype in the PNPLA3 gene and TT genotype in the MBOAT7 gene were independent predictors of advanced fibrosis (Table 6).

PNPLA3 and MBOAT7 and correlation with baseline characteristics and laboratory tests

The association analysis showed that carriers of GG genotype in the PNPLA3 gene had significantly higher serum creatinine than carriers of homozygous or heterozygous $\mathrm{C}$ allele ( $\mathrm{p}=0.036$ ). On the other hand, the viral load of HCV RNA was significantly lower among carriers of GG genotype in PNPLA3 gene than carries of homozygous or heterozygous $\mathrm{C}$ allele ( $\mathrm{p}$ 0.045). Female patients were less likely to have GG genotype than male patients ( $p=0.041$; Table 4). Compared to combined $\mathrm{CC}$ and $\mathrm{GC}$ genotypes, carriers of GG genotype in the PNPLA3 gene were more likely to be males ( $p=0.041$ ), have higher fibrosis grade ( $p=0.043$ ), have higher serum creatinine ( $\mathrm{p}=0.036)$, higher TSH $(\mathrm{p}=0.017)$, and higher viral load ( $p=0.045$ ) (Table 4).

Compared to $\mathrm{CC}$ and $\mathrm{CT}$ genotypes, carriers of TT genotype in the MBOAT7 gene were more likely to be older ( $\mathrm{p}=0.046$ ). The association analysis showed that carriers of TT genotype in the MBOAT7 gene had significantly higher serum AFP than carriers of homozygous or heterozygous $C$ allele ( $p=0.001$ ). On the other hand, non-smokers had a significantly higher frequency of TT genotype in the MBOAT7 gene $(p=0.016)$. Notably, we found no significant association between TT genotype in MBOAT7 and necroinflammation ( $p>0.05$ table 5).

Results of an additive effect of PNPLA3-MBOAT7 genotypes on fibrosis

Studying the additive effect of PNPLA3MBOAT7 polymorphisms genotypes among patients with advanced fibrosis included in our study showed that the frequency of CC-TT haplotype of PNPLA3MBOAT7 was higher in patients with milder degrees of hepatic fibrosis, whereas the expression of CG -TT haplotype was correlated to more advanced fibrosis stage (F4) with significant statistical analysis $(\mathrm{p}=0.001)$ as shown in table $(\mathbf{7})$. 
Table (1): Demographic and clinical data of the studied patients

\begin{tabular}{|l|l|}
\hline Parameters & Patients results \\
\hline Age (mean \pm S.D) & $42.72 \pm 10.46$ \\
\hline Males \% & $49.5 \%$ \\
\hline BMI kg/m2 (mean \pm SD) & $29.07 \pm 4.15$ \\
\hline AST IU/l (mean \pm S.D) & $40.94 \pm 28.44$ \\
\hline ALT IU/l (mean \pm S.D) & $36.61 \pm 25.05$ \\
\hline AFP ng/ml (mean \pm S.D) & $9.75 \pm 18.09$ \\
\hline PLT mm3(mean \pm S.D) & $172390.80 \pm 49917.22$ \\
\hline Albumin g/dL (mean \pm SD) & $3.98 \pm 0.55$ \\
\hline Creatinine mg/dl (mean \pm S.D) & $0.88 \pm 0.19$ \\
\hline AFP ng/ml (mean \pm S.D) & $9.75 \pm 18.09$ \\
\hline Total bilirubin mg/dL (mean \pm S.D) & $0.81 \pm 0.41$ \\
\hline Viral load IU/ml (mean \pm S.D) & $1081484.31 \pm 3176736.93$ \\
\hline Fibrosis \% & $36.60 \%$ \\
F1 & $21.50 \%$ \\
F2 & $29.00 \%$ \\
F3 & $12.90 \%$ \\
F4 & $68.60 \%$ \\
\hline Activity \% & $27.10 \%$ \\
A1 & $4.3 \%$ \\
A2 & \\
A3 &
\end{tabular}

SD: standard deviation; BMI: body mass index; ALT: alanine aminotransferase; AST: aspartate aminotransferase; PLT: platelet count; AFP: alfa fetoprotein.

Table (2): genotype distribution of PNPLA3 rs738409 and MBOAT7 rs 641738 in studied patients

\begin{tabular}{|c|c|c|}
\hline \multicolumn{1}{|c|}{ Parameters } & Groups & N (Percent) \\
\hline \multirow{2}{*}{ PNPLA3 rs738409 } & CC & $43(46.20 \%)$ \\
\cline { 2 - 3 } & CG & $40(43.00 \%)$ \\
\cline { 2 - 3 } & GG & $10(10.80 \%)$ \\
\hline \multirow{2}{*}{ MBOAT7 rs641738 } & CC & $21(22.60 \%)$ \\
\cline { 2 - 3 } & CT & $29(31.20 \%)$ \\
\cline { 2 - 3 } & TT & $43(46.20 \%)$ \\
\hline
\end{tabular}

$\mathrm{N}$ : number 
Table (3) Genotype distribution of PNPLA3 rs738409 and MBOAT7 rs 641738 in studied patients according to fibrosis.

A)

\begin{tabular}{|c|c|c|c|}
\hline \multirow{2}{*}{ Parameters } & \multicolumn{2}{|c|}{ PNPLA3 } & \multirow{2}{*}{ P value } \\
\cline { 2 - 4 } & CC+CG & GG & \\
\hline Fibrosis & $28(33.7 \%)$ & N(\%) & \\
F1 & $19(22.9 \%)$ & $1(10 \%)$ & 0.043 \\
F2 & $27(32.5 \%)$ & $0(0 \%)$ & \\
F3 & $9(10.8 \%)$ & $3(30 \%)$ & \\
F4 & & & \\
\hline A & $52(67.7 \%)$ & $1(12.5 \%)$ & 0.335 \\
A1 & $23(29.1 \%)$ & $1(12.5 \%)$ & \\
A2 & $8(3.2 \%)$ & & \\
A3 & & & \\
\hline
\end{tabular}

$\mathrm{N}$ : number

B)

\begin{tabular}{|c|c|c|c|c|}
\hline \multirow{2}{*}{ Parameters } & \multirow{2}{*}{ Groups } & \multicolumn{2}{|c|}{ MBOAT7 rs641738 } & \multirow{2}{*}{ P-value } \\
\hline & & $\mathrm{CC}+\mathrm{CT} \mathrm{N}(\%)$ & TT N(\%) & \\
\hline \multirow{2}{*}{ Fibrosis } & $\begin{array}{l}\text { F1 } \\
\text { F2 } \\
\text { F3 } \\
\text { F4 } \\
\end{array}$ & $\begin{array}{l}21(42 \%) \\
10(20 \%) \\
16(32 \%) \\
3(6 \%) \\
\end{array}$ & $\begin{array}{l}13(30.2 \%) \\
10(23.3 \%) \\
11(25.6 \%) \\
9(20.9 \%)\end{array}$ & 0.150 \\
\hline & $\begin{array}{l}\text { F4 } \\
\text { F0-F3 }\end{array}$ & $\begin{array}{l}3(6 \%) \\
47(94 \%)\end{array}$ & $\begin{array}{l}9(20.9 \%) \\
34(79.1 \%)\end{array}$ & 0.032 \\
\hline Activity & $\begin{array}{l}\text { A1 } \\
\text { A2 } \\
\text { A3 }\end{array}$ & $\begin{array}{l}27(65.9 \%) \\
11(26.8 \%) \\
3(7.3 \%)\end{array}$ & $\begin{array}{l}21(72.4 \%) \\
8(27.6 \%) \\
0(0 \%)\end{array}$ & 0.328 \\
\hline
\end{tabular}

$\mathrm{N}$ : number 
Table (4): PNPLA3 genotypes concerning patient's characteristics

\begin{tabular}{|c|c|c|c|}
\hline \multirow{2}{*}{ Parameters } & \multicolumn{2}{|c|}{ PNPLA3 } & \multirow{2}{*}{ P-value } \\
\hline & $\mathrm{CC}+\mathrm{CG}$ & GG & \\
\hline $\begin{array}{l}\text { Age } \\
(\text { mean } \pm \text { S.D) }\end{array}$ & $43.43 \pm 10.46$ & $36.80 \pm 8.82$ & 0.058 \\
\hline $\begin{array}{l}\text { Gender } \\
\text { Male (no \%) } \\
\text { Female (no \%) }\end{array}$ & $\begin{array}{l}38(45.8 \%) \\
45(54.2 \%)\end{array}$ & $\begin{array}{l}8(80 \%) \\
2(20 \%)\end{array}$ & 0.041 \\
\hline $\begin{array}{l}\text { Diabetes } \\
\text { Positive } \\
\text { negative }\end{array}$ & $\begin{array}{l}15(20.3 \%) \\
59(79.7 \%)\end{array}$ & $\begin{array}{l}0(0 \%) \\
8(100 \%)\end{array}$ & 0.159 \\
\hline $\mathrm{BMI} \mathrm{kg} / \mathrm{m} 2($ mean \pm S.D) & $29.25 \pm 4.22$ & $27.61 \pm 3.28$ & 0.239 \\
\hline $\mathrm{Hb}$ gm/dL (mean \pm S.D) & $13.51 \pm 1.60$ & $13.93 \pm 1.88$ & 0.449 \\
\hline PLT mm3(mean \pm S.D) & $195451.22 \pm 64311.96$ & $203800.00 \pm 85565.83$ & 0.710 \\
\hline AST IU / L(mean \pm S.D $)$ & $68.33 \pm 40.50$ & $84.60 \pm 61.67$ & 0.476 \\
\hline ALT IU/L (mean \pm S.D) & $69.47 \pm 49.23$ & $99.20 \pm 66.62$ & 0.157 \\
\hline $\begin{array}{l}\text { Creatinine } \mathrm{mg} / \mathrm{dl} \text { (mean } \\
\pm \text { S.D) }\end{array}$ & $0.82 \pm 0.20$ & $1.00 \pm 0.09$ & 0.036 \\
\hline $\begin{array}{l}\operatorname{TLC}(10 / \mu l)^{3}(\text { mean } \pm \\
\text { S.D) }\end{array}$ & $5329.70 \pm 2800.66$ & $3903.07 \pm 4297.36$ & 0.602 \\
\hline $\mathrm{TSH} \mathrm{mU} / \mathrm{L}($ mean $\pm \mathrm{S} . \mathrm{D})$ & $1.81 \pm 1.03$ & $0.89 \pm 0.21$ & 0.017 \\
\hline AFP ng/ml (mean \pm S.D) & $10.43 \pm 18.99$ & $3.91 \pm 2.68$ & 0.197 \\
\hline $\begin{array}{l}\text { Albumin g/dL (mean } \pm \\
\text { S.D) }\end{array}$ & $3.97 \pm 0.55$ & $4.05 \pm 0.59$ & 0.673 \\
\hline $\begin{array}{l}\text { T bilirubin } \mathrm{mg} / \mathrm{dL} \text { (mean } \\
\pm \mathrm{S} . \mathrm{D} \text { ) }\end{array}$ & $0.80 \pm 0.37$ & $1.49 \pm 1.91$ & 0.232 \\
\hline $\begin{array}{l}\text { Viral load IU/ml } \\
\text { (mean } \pm \text { S.D) }\end{array}$ & $1191500.00 \pm 3329810.00$ & $78888.11 \pm 118465.00$ & 0.045 \\
\hline
\end{tabular}

SD: standard deviation; BMI: body mass index; Hb: hemoglobin; PLT: platelet count; AST: aspartate aminotransferase; ALT: alanine aminotransferase; TLC: total Leukocytes Count; TSH: thyroid-stimulating hormone; AFP: alfa fetoprotein; T bilirubin: total bilirubin.

Table (5): MBOAT7 genotypes concerning lab profile of the studied patients 


\begin{tabular}{|c|c|c|c|}
\hline \multirow{2}{*}{ Parameters } & \multicolumn{2}{|c|}{ MBOAT7 } & \multirow{2}{*}{ P-value } \\
\hline & $\mathrm{CC}+\mathrm{CT}$ & $T \mathrm{TT}$ & \\
\hline Age (mean \pm S.D) & $40.76 \pm 11.64$ & $45.00 \pm 8.46$ & 0.046 \\
\hline $\begin{array}{ll}\text { Gender } & \text { Male } \\
& \text { Female }\end{array}$ & $\begin{array}{l}28(56 \%) \\
22(44 \%)\end{array}$ & $\begin{array}{l}18(41.9 \%) \\
25(58.1 \%)\end{array}$ & 0.174 \\
\hline $\mathrm{BMI} \mathrm{kg} / \mathrm{m} 2($ mean $\pm \mathrm{S} . \mathrm{D})$ & $28.92 \pm 4.72$ & $29.25 \pm 3.38$ & 0.705 \\
\hline $\mathrm{Hb}$ gm/dL (mean \pm S.D) & $13.75 \pm 1.60$ & $13.34 \pm 1.66$ & 0.235 \\
\hline PLT mm3 (mean \pm S.D) & $\begin{array}{c}204346.94 \pm \\
59442.74\end{array}$ & $187255.81 \pm 73231.24$ & 0.220 \\
\hline AST IU/L (mean \pm S.D) & $70.40 \pm 46.50$ & $69.70 \pm 39.39$ & 0.686 \\
\hline ALT IU/L (mean \pm S.D) & $79.98 \pm 62.53$ & $64.16 \pm 34.22$ & 0.410 \\
\hline Creatinine mg/dl (mean \pm S.D) & $0.86 \pm 0.22$ & $0.82 \pm 0.18$ & 0.487 \\
\hline AFP ng/ml (mean \pm S.D) & $5.20 \pm 6.72$ & $14.74 \pm 24.43$ & 0.001 \\
\hline T bilirubin mg/dL (mean \pm S.D) & $0.93 \pm 0.87$ & $0.81 \pm 0.44$ & 0.533 \\
\hline Viral load IU/ml & $\begin{array}{c}1309600.00 \pm \\
3638990.00\end{array}$ & $815352.24 \pm 2552360.00$ & 0.514 \\
\hline $\begin{array}{l}\text { Diabetes } \\
\text { Positive } \\
\text { Negative }\end{array}$ & $\begin{array}{c}7(16.7 \%) \\
35(83.3 \%)\end{array}$ & $\begin{array}{c}8(20 \%) \\
32(80 \%)\end{array}$ & 0.696 \\
\hline $\begin{array}{l}\text { SMOKING } \\
\text { Positive } \\
\text { Negative }\end{array}$ & $\begin{array}{c}5(14.7 \%) \\
29(85.3 \%)\end{array}$ & $\begin{array}{c}3(8.3 \%) \\
33(91.7 \%)\end{array}$ & 0.402 \\
\hline $\begin{array}{c}\text { Activity } \\
\text { A1 } \\
\text { A2 } \\
\text { A3 }\end{array}$ & $\begin{array}{c}27(65.9 \%) \\
11(26.8 \%) \\
3(7.3 \%)\end{array}$ & $\begin{array}{c}21(72.4 \%) \\
8(27.6 \%) \\
0(0 \%)\end{array}$ & 0.328 \\
\hline $\begin{array}{c}\text { Fibrosis } \\
\text { F1 } \\
\text { F2 } \\
\text { F3 } \\
\text { F4 }\end{array}$ & $\begin{array}{c}21(42 \%) \\
10(20 \%) \\
16(32 \%) \\
3(6 \%)\end{array}$ & $\begin{array}{c}13(30.2 \%) \\
10(23.3 \%) \\
11(25.6 \%) \\
9(20.9 \%)\end{array}$ & 0.150 \\
\hline
\end{tabular}

Figure (1): Fibrosis stages in different genotypes of PNPLA3 


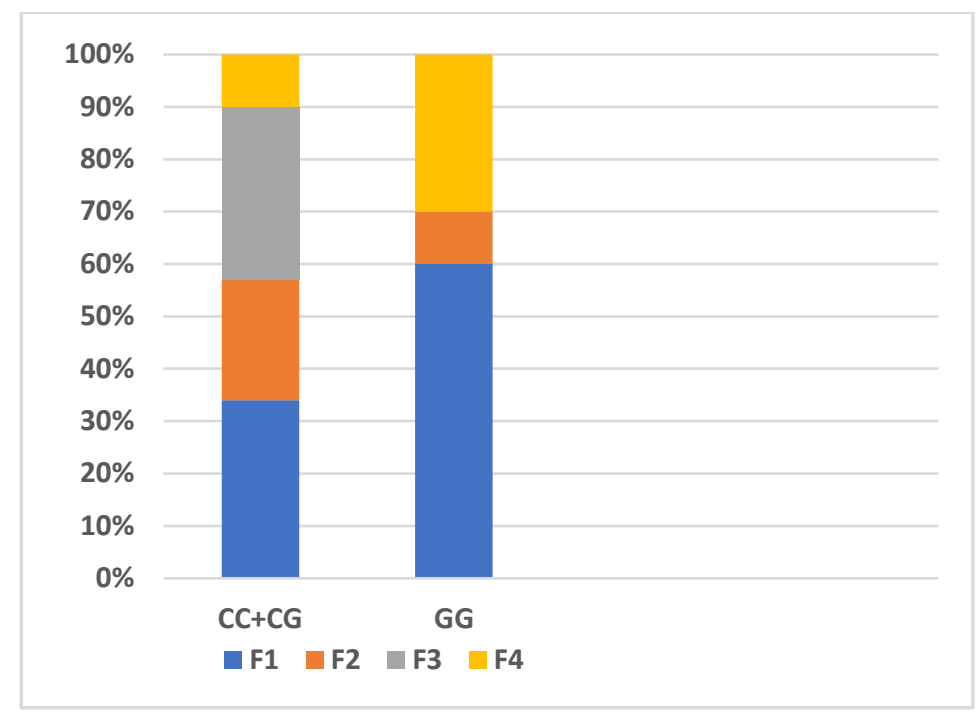

Table (6): Multivariate analysis for fibrosis (F1F2F3 vs F4) using Stepwise method:

\begin{tabular}{|l|l|l|l|l|}
\hline Parameters & Coefficient & Odds Ratio & $\mathbf{9 5 . 0 \%}$ C.I. for EXP(B) & P-value \\
\hline BMI & 0.177 & 1.194 & 1.003 to 1.421 & 0.046 \\
\hline PNPLA3 & 1.109 & 3.033 & 1.072 to 8.576 & 0.036 \\
\hline MBOAT7 & 1.463 & 4.321 & 1.174 to 15.905 & 0.028 \\
\hline
\end{tabular}

BMI: body mass index.

Table (7): Effect of the combined genotypes of PNPLA3-MBOAT7 on fibrosis

\begin{tabular}{|c|c|c|c|}
\hline $\begin{array}{c}\text { Haplotype } \\
\text { PNPLA3-MBOAT7 }\end{array}$ & F4 & F0-F3 & P-value \\
\hline CC-CC & $0(0.00 \%)$ & $9(11.10 \%)$ & \\
\hline CC-CT & $1(8.30 \%)$ & $14(17.30 \%)$ & \multirow{2}{*}{0.001} \\
\hline CC-TT & $2(16.70 \%)$ & $17(21.00 \%)$ & \\
\hline CG-CC & $0(0.00 \%)$ & $10(12.30 \%)$ & \\
\hline CG-CT & $0(0.00 \%)$ & $12(14.80 \%)$ & \\
\hline CG-TT & $6(50.00 \%)$ & $2(2.50 \%)$ & \\
\hline GG-CC & $0(0.00 \%)$ & $0(0.00 \%)$ & \\
\hline GG-CT & $2(16.70 \%)$ & $5(6.20 \%)$ & \\
\hline GG-TT & $1(8.30 \%)$ & & \\
\hline
\end{tabular}




\section{Discussion}

To the best of our knowledge, this is the first Egyptian study that aimed to assess the correlation between the SNPs in MBOAT7 \& PNPLA3 genes and fibrosis in $\mathrm{HCV}$ Egyptian patients. Our findings showed that the distribution of PNPLA3 CC and CG genotypes was comparable ( $46.2 \%$ vs $43.0 \%$ ), PNPLA3 GG genotype was detected only in $10.8 \%$ of the Egyptian patients. This study indicates a nonsignificant difference between PNPLA3 genotypes in terms of gender, diabetes, smoking, BMI, HbA1c, PLT, AST, ALT, TLC, AFP, and Albumin. On the other hand, patients with PNPLA3 CG genotype tend to be older than CC and GG carriers $(\mathrm{p}=0.038)$ and have a lower level of creatinine $(p=0.034)$. Interestingly, a higher level of viremia $\left(15 \times 10^{5}\right)$ was observed in the CG genotype patients compared to $9 \times 10^{5}$ in the CC genotype and $7 \times 10^{4}$ in the GG genotype group $(\mathrm{p}=0.016)$.

Compared to the GG genotype, the polymorphism of $\mathrm{CC}+\mathrm{CG}$ genotypes was more frequent in females $(\mathrm{p}=0.041)$. A significant association between the $\mathrm{CC}+\mathrm{CG}$ genotypes polymorphism and the severity of fibrosis was observed ( $\mathrm{p}=0.043)$. Sato and colleagues showed that the $\mathrm{CG}$ was the most common genotype (49.2\%) in Japanese patients with CHC. They also demonstrated a highly significant association between the $\mathrm{CC}+\mathrm{CG}$ polymorphism, females, and high $\mathrm{BMI}$ and the older age at onset of $\mathrm{HCC}(\mathrm{p}<0.001, \mathrm{p}=0.004$, and $\mathrm{p}=0.03$, respectively) (18). These findings indicate that males with $\mathrm{HCV}$ and patients with GG polymorphism were more prone to develop HCC in a shorter time $(p<0.001)$. Moreover, they found that the GG genotype was associated with higher ALT \& AST and lower PT, which suggests depressed liver function (18). This finding was in agreement with our findings; however, the difference was not significant.
According to Crisan et al., the presence of the $G$ allele either homozygous GG or heterozygous CG strongly correlated with steatosis and fibrosis, while genotype $\mathrm{C}$ appears to be inversely correlated with these variables (19). This finding is also confirmed by Romeo et al., who reported a significantly 2-fold increase in the risk of developing NAFLD and progression in the presence of adiponutrin allele $\mathrm{G}(9)$. It was also reported that the PNPLA3 $\mathrm{G}$ allele is an independent predictor for severe (S2-S3) steatosis and significantly associated with advanced (F3 - F4) fibrosis (19). A meta-analysis of five studies and more than 2000 patients showed that the $G$ allele was a predictor for severe steatosis and fibrosis, especially in Caucasian populations (20). Another meta-analysis conducted by Fan et al., confirmed these findings; GG of PNPLA3 was associated with a higher risk of both advanced liver fibrosis and liver steatosis in Caucasian populations (13). Furthermore, two large Asian studies demonstrated an association between the $\mathrm{G}$ allele and hepatic steatosis $(21,22)$. Petta et al., found a significant correlation between steatosis severity and the $G$ variant, while also accounting for steatohepatitis (23). Another Italian study showed that the PNPLA3 G allele is promoting fibrosis (11).

The impact of the PNPLA3 mutant allele on fibrogenesis seems to be tied in the hepatic stellate cell (HSC) to the retinoid metabolism (24). This function is lost by the PNPLA3 $\mathrm{G}$ allele, thereby increasing the retinyl palmitate and palmitate retinol ratio within HSCs $(25,26)$. As a result, a fibrogenesis imbalance appears to be produced between matrix metallopeptidase 2 (MMP2) secretion and tissue inhibitors of metalloproteinase 1 and 2 (TIMP1 and TIMP2) (27).

In terms of MBOAT7, the TT genotype was the most common in the Egyptians (46.20\%), followed by the CT genotype (31.20\%). Interestingly, a negative 
association was observed between smoking and $M B O A T 7$ polymorphism, the majority of patients with a high frequency of MBOAT7 were non-smokers $(\mathrm{p}=0.016)$. Regarding the AFP, TT genotype patients were associated with higher levels of AFP compared to $\mathrm{CC}, \mathrm{CT}$, and $\mathrm{CC}+\mathrm{CT}(\mathrm{p}=0.002)$. Notably, we found a significant association between TT genotype in MBOAT7 and advanced fibrosis (F4) but not with necroinflammation.

Krawczyk et al., also showed that there was no association between MBOAT7 SNPs and hepatic steatosis; (28). A recent meta-analysis by Xia et al., showed that MBOAT7 SNPs were not related to NAFLD risks (29). In the Asian population, Koo et al., demonstrated that there was no relation between MBOAT7 and the development of NAFLD (30). In CHC patients, Thabet K. et al. observed that MBOAT7 rs641738 was independently associated with inflammation and the transition to early fibrosis; as its expression correlates with inflammation; whereas rs641738 genotypes have no association with the severity of hepatic steatosis or HCC occurrence (31). These varying findings clearly show that the outcome of chronic liver injury may have a different effect from genetic factors in different populations.

In the study of Basyte-Bacevice et al. (32), they showed that the MBOAT7 CT genotype was the most frequent genotype in patients with liver fibrosis $(51.56 \%)$ and cirrhosis $(47.90 \%)$. However, a comparable percentage was also observed in the controls (47.45\%). Similarly, in the alcohol cirrhotic and $\mathrm{HCV}$-induced cirrhotic patients, the CT genotype was the most frequent genotype. These findings indicated that there was no significant association between MBOAT7 SNPs and hepatic fibrosis or cirrhosis in the Eastern European population.

Comparatively, in our study involving patients with $\mathrm{HCV}$-related liver fibrosis, a significant correlation was confirmed where patients with advanced liver fibrosis showed expression of the CG-TT haplotypes, while patients with mild degrees of fibrosis showed the CCTT haplotypes. Our results may have differed because of the different etiology of liver fibrosis among the patients included in both studies.

In conclusion, our study showed that in the Egyptian population, the $\mathrm{CC}+\mathrm{CG}$ genotypes of PNPLA3 and TT genotype of MBOAT7 are the most frequently detected. PNPLA3 $\mathrm{CC}+\mathrm{CG}$ genotypes are a reliable predictor for hepatic fibrosis, and therefore might be linked to faster disease progression, while MBOAT7 could not be directly correlated to hepatic necroinflammation or fibrosis degree. Thus, this genetic factor should be taken into consideration when determining a treatment strategy. While we cannot fight our genes, we can improve outcomes by correcting metabolic imbalances, fighting against obesity and metabolic syndrome, and therefore, halting the progression of fibrosis.

\section{Funding}

Has not received any funding.

\section{Disclosure}

All authors have declared no conflicts of interest.

\section{References}

1. Shepard CW, Finelli L, Alter MJ. Global epidemiology of hepatitis $\mathrm{C}$ virus infection. The Lancet infectious diseases. 2005;5(9):558-67.

2. Barrera JM, Bruguera M, Ercilla MG, Gil C, Celis R, Gil MP, et al. Persistent hepatitis C viremia after acute self-limiting posttransfusion hepatitis C. Hepatology. 1995;21(3):639-44.

3. Karlsen TH, Lammert F, Thompson RJ. Genetics of liver disease: from pathophysiology to 
clinical practice. Journal of Hepatology. 2015;62(1): S6-S14.

4. Tsochatzis EA, Bosch J, Burroughs AK. Liver cirrhosis. The Lancet. 2014;383(9930):1749-61.

5. D'Ambrosio R, Aghemo A, De Francesco R, Rumi MG, Galmozzi E, De Nicola $\mathrm{S}$, et al. The association of IL28B genotype with the histological features of chronic hepatitis $\mathrm{C}$ is $\mathrm{HCV}$ genotype dependent. International journal of molecular sciences. 2014;15(5):7213-24.

6. Weber SN, Lammert F. Genetics of liver injury and fibrosis. Alcoholism: Clinical and Experimental Research. 2011;35(5):800-3.

7. Trépo E, Pradat P, Potthoff A, Momozawa Y, Quertinmont E, Gustot T, et al. Impact of patatin-like phospholipase-3 (rs738409 $\mathrm{C}>\mathrm{G}$ ) polymorphism on fibrosis progression and steatosis in chronic hepatitis $\mathrm{C}$. Hepatology. 2011;54(1):60-9.

8. Valenti L, Rumi M, Galmozzi E, Aghemo A, Del Menico B, De Nicola S, et al. Patatin-like phospholipase domain-containing 3 I148M polymorphism, steatosis, and liver damage in chronic hepatitis C. Hepatology. 2011;53(3):791-9.

9. Romeo S, Kozlitina J, Xing C, Pertsemlidis A, Cox D, Pennacchio LA, et al. Genetic variation in PNPLA3 confers susceptibility to nonalcoholic fatty liver disease. Nature genetics. 2008;40(12):1461-5.

10. Kawaguchi T, Sumida Y, Umemura A, Matsuo K, Takahashi M, Takamura T, et al. Genetic polymorphisms of the human PNPLA3 gene are strongly associated with severity of non-alcoholic fatty liver disease in Japanese. PloS one. 2012;7(6):e38322.

11. Kupcinskas J, Valantiene I, Varkalaitė G, Steponaitiene R, Skieceviciene J, Sumskiene J, et al.
PNPLA3 and RNF7 Gene Variants are Associated with the Risk of Developing Liver Fibrosis and Cirrhosis in an Eastern European Population. Journal of Gastrointestinal \& Liver Diseases. 2017;26(1).

12. Buch S, Stickel F, Trépo E, Way M, Herrmann A, Nischalke HD, et al. A genome-wide association study confirms PNPLA3 and identifies TM6SF2 and MBOAT7 as risk loci for alcohol-related cirrhosis. Nature genetics. 2015;47(12):1443-8.

13. Fan J-H, Xiang M-Q, Li Q-L, Shi H-T, Guo JJ. PNPLA3 rs738409 polymorphism associated with hepatic steatosis and advanced fibrosis in patients with chronic hepatitis $\mathrm{C}$ virus: a meta-analysis. Gut and liver. 2016;10(3):456.

14. Mancina RM, Dongiovanni P, Petta S, Pingitore P, Meroni M, Rametta R, et al. The MBOAT7-TMC4 variant rs641738 increases risk of nonalcoholic fatty liver disease in individuals of European descent. Gastroenterology. 2016;150(5):1219-30. e6.

15. Donati B, Dongiovanni P, Romeo S, Meroni M, McCain M, Miele L, et al. MBOAT7 rs641738 variant and hepatocellular carcinoma in non-cirrhotic individuals. Scientific reports. 2017;7(1):1-10.

16. Youssef SS, Abbas EAER, Youness RA, Elemeery MN, Nasr AS, Seif S. PNPLA3 and IL 28B signature for predicting susceptibility to chronic hepatitis $\mathrm{C}$ infection and fibrosis progression. Archives of Physiology and Biochemistry. 2019:1-7.

17. Bedossa P, Poynard T. An algorithm for the grading of activity in chronic hepatitis C. Hepatology. 1996;24(2):289-93.

18. Sato M, Kato N, Tateishi R, Muroyama R, Kowatari N, Li W, et al. Impact of PNPLA3 polymorphisms on the development of hepatocellular 
carcinoma in patients with chronic hepatitis $\mathrm{C}$ virus infection. Hepatology Research. 2014;44(10): E137E44.

19. Crisan D, Grigorescu M, Crisan N, Craciun R, Lupsor M, Radu C, et al. Association between PNPLA3 $[\mathrm{G}] / \mathrm{I} 148 \mathrm{M}$ variant, steatosis and fibrosis stage in hepatitis $\mathrm{C}$ virus-genetics matters. Journal of Physiology and Pharmacology. 2019;70(4):585-93.

20. Leandro G, Mangia A, Hui J, Fabris P, Rubbia-Brandt L, Colloredo G, et al. Relationship between steatosis, inflammation, and fibrosis in chronic hepatitis $\mathrm{C}$ : a meta-analysis of individual patient data. Gastroenterology. 2006;130(6):1636-42.

21. Huang C-M, Chang K-C, Hung C-H, Chiu KW, Lu S-N, Wang J-H, et al. Impact of PNPLA3 and IFNL3 polymorphisms on hepatic steatosis in Asian patients with chronic hepatitis C. PloS one. 2017;12(8):e0182204.

22. Huang C-F, Chen J-J, Yeh M-L, Huang C-I, Hsieh M-Y, Yang H-L, et al. PNPLA3 genetic variants determine hepatic steatosis in non-obese chronic hepatitis C patients. Scientific reports. 2015;5(1):1-9.

23. Petta S, Vanni E, Bugianesi E, Rosso C, Cabibi $\mathrm{D}$, Cammà $\mathrm{C}$, et al. PNPLA 3 rs738409 I748M is associated with steatohepatitis in 434 non-obese subjects with hepatitis C. Alimentary Pharmacology \& Therapeutics. 2015;41(10):939-48.

24. Pirazzi C, Adiels M, Burza MA, Mancina RM, Levin M, Ståhlman M, et al. Patatin-like phospholipase domain-containing 3 (PNPLA3) I148M (rs738409) affects hepatic VLDL secretion in humans and in vitro. Journal of hepatology. 2012;57(6):1276-82.

25. Pirazzi C, Valenti L, Motta BM, Pingitore P, Hedfalk K, Mancina RM, et al. PNPLA3 has retinyl- palmitate lipase activity in human hepatic stellate cells. Human molecular genetics. 2014;23(15):4077-85.

26. Kovarova M, Königsrainer I, Königsrainer A, Machicao F, Häring H-U, Schleicher E, et al. The genetic variant I148M in PNPLA3 is associated with increased hepatic retinyl-palmitate storage in humans. The Journal of Clinical Endocrinology \& Metabolism. 2015;100(12):E1568-E74.

27. Pingitore $\mathrm{P}$, Dongiovanni $\mathrm{P}$, Motta $\mathrm{BM}$, Meroni M, Lepore SM, Mancina RM, et al. PNPLA3 overexpression results in reduction of proteins predisposing to fibrosis. Human molecular genetics. 2016;25(23):5212-22.

28. Krawczyk M, Rau M, Schattenberg JM, Bantel H, Pathil A, Demir M, et al. Combined effects of the PNPLA3 rs738409, TM6SF2 rs58542926, and MBOAT7 rs641738 variants on NAFLD severity: a multicenter biopsy-based study. Journal of lipid research. 2017;58(1):247-55.

29. Xia Y, Huang C-X, Li G-Y, Chen K-H, Han L, Tang L, et al. Meta-analysis of the association between MBOAT7 rs641738, TM6SF2 rs58542926 and nonalcoholic fatty liver disease susceptibility. Clinics and research in hepatology and gastroenterology. 2019;43(5):533-41.

30. Koo BK, Joo SK, Kim D, Bae JM, Park JH, $\mathrm{Kim} \mathrm{JH}$, et al. Additive effects of PNPLA3 and TM6SF2 on the histological severity of non-alcoholic fatty liver disease. Journal of Gastroenterology and Hepatology. 2018;33(6):1277-85.

31. Thabet K, Asimakopoulos A, Shojaei M, Romero-Gomez M, Mangia A, Irving WL, et al. MBOAT7 rs641738 increases risk of liver inflammation and transition to fibrosis in chronic hepatitis C. Nature communications. 2016;7(1):1-8. 
32. Basyte-Bacevice V, Skieceviciene J, variants in liver fibrosis and cirrhosis. International Valantiene I, Sumskiene J, Petrenkiene V, journal of molecular sciences. 2019;20(6):1277. Kondrackiene J, et al. TM6SF2 and MBOAT7 gene 